\title{
Hematología y química sanguínea de la codorniz japonesa (Coturnix coturnix japonica)
}

Hematology and blood chemistry of Japanese quail (Coturnix coturnix

\author{
japonica)
}

\begin{abstract}
Caicedo Álvarez Camilo Andrés ${ }^{1}$, Hurtado Nery Víctor Libardo², Torres Novoa Diana Milena ${ }^{3}$ y Fuentes Reyes Edgar Edilberto ${ }^{2}$ ${ }^{1}$ Médico Veterinario Zootecnista, Universidad de los Llanos, ${ }^{2}$ Médicos Veterinarios Zootecnistas. Esp. MSc. PhD. Docentes de la Universidad de los Llanos y ${ }^{3}$ Médica Veterinaria Zootecnista MSc. Docente de la Universidad Abierta y a Distancia

\section{vhurtado@unillanos.edu.co}

Recibido 02 de Diciembre 2015, Aceptado 29 de Abril 2016

\section{RESUMEN}

El presente trabajo se realizó con el objetivo de determinar los valores de hematología y química sanguínea de la codorniz japonesa en la ciudad de Villavicencio, ya que en la actualidad no se encuentran resultados de estudios sobre este tema realizados en el país y en especial en la Región de la Orinoquía, a la vez se determinó cómo puede afectarse el metabolismo, cuando componentes esenciales de la dieta como lo son los aminoácidos L-lisina y DL-metionina se encuentran en diferentes niveles. Se emplearon 36 codornices de 45 días de edad, con peso promedio de $155.5 \mathrm{~g}$, en un diseño experimental completamente al azar con tres tratamientos, cuatro repeticiones y tres aves por unidad experimental. Los tratamientos estaban constituidos por ración basal $1.036 \%$ de lisina y $0.393 \%$ de metionina. Se realizó análisis de varianza mediante el software de análisis estadístico Statisitical Analysis Sistem, SAS ${ }^{\circledR}$. Las variables evaluadas fueron conteo total de eritrocitos, hemoglobina, hematocrito, volumen corpuscular medio, trombocitos, recuento diferencial de leucocitos, glucosa, lactosa, calcio, potasio, sodio, dióxido de carbono total, bicarbonato, saturación de oxígeno, presión parcial de dióxido de carbono y $\mathrm{pH}$ sanguíneo. Los parámetros de hematología, bioquímica y gases en sangre para codornices japonesas no fueron afectados $(P>0.05)$ por los tratamientos evaluados excepto para el recuento de 
leucocitos y la saturación de oxígeno en sangre. En conclusión, la suplementación de aminoácidos sintéticos L-lisina y DL-metionina aumenta el porcentaje de saturación de oxígeno en sangre, y niveles de $0.153 \%$ de lisina en la dieta pueden favorecer el sistema inmune de codornices japonesas en fase de postura, previniendo la aparición de patologías que afectan los sistemas productivos.

Palabras clave: Perfiles metabólicos, aminoácidos, metionina, lisina, huevo.

\section{ABSTRACT}

This work was performed in order to determine the values of hematology and blood chemistry of Japanese quail in the Villavicencio city, because at present no are found results of studies on this issue conducted in the country and especially in the Orinoco's region, at a time determines how metabolism can be affected, when essential components of the diet as are the amino acids L-lysine and DLmethionine are at different levels. 36 quail 45 days old were used, with an average weight of $155.5 \mathrm{~g}$, in a completely randomized experimental design with three treatments, four replicates and three birds per experimental unit. The treatments were composed of basal diet $1.036 \%$ of lysine and $0.393 \%$ of methionine. Analysis of variance was performed using statistical analysis software Statisitical Sistem Analysis, $\mathrm{SAS}^{\circledR}$. The variables evaluated were total count of erythrocytes, hemoglobin, hematocrit, mean corpuscular volume, thrombocytes, differential leukocyte count, glucose, lactose, calcium, potassium, sodium, total carbon dioxide, bicarbonate, oxygen saturation, partial pressure dioxide carbon and blood $\mathrm{pH}$. In conclusion supplementation of synthetic amino acids L-lysine and DLmethionine increases the percentage of blood oxygen saturation, and levels of $0.153 \%$ lysine in the diet may favor the immune system of Japanese quail in stance phase, preventing the appearance of pathologies that affect production systems.

Keywords: Metabolic profiles, amino acid, methionine, lysine, egg. 


\section{RESUMO}

Este trabalho foi realizado a fim de determinar os valores de hematologia e química do sangue de codornas japonesas na cidade de Villavicencio, já que atualmente não existem resultados de estudos sobre o tema realizados no país e especialmente na região do Orinoco, tanto que é determinou como o metabolismo pode ser afetado, quando os componentes essenciais da dieta assim como os aminoácidos L-lisina e DL-metionina estão em níveis diferentes. 36 codornas 45 dias de idade foram usados, com um peso médio de $155.5 \mathrm{~g}$, em um delineamento experimental inteiramente casualizado, com três tratamentos, quatro repetições e três aves por unidade experimental. Os tratamentos foram compostos da dieta basal $1.036 \%$ de lisina e $0.393 \%$ de metionina. Análise de variância foi realizada utilizando o software de análise estatístico Statisitical Analysis Sistem, SAS ${ }^{\circledR}$. As variáveis avaliadas foram contagem total de eritrócitos, hemoglobina, hematócrito, volume corpuscular médio, trombócitos, contagem diferencial de leucócitos, glicose, lactose, cálcio, potássio, sódio, dióxido de carbono total, bicarbonato, saturação de oxigênio, dióxido de pressão parcial carbono e pH do sangue. Em conclusão o suplementação de aminoácidos sintético L-lisina e DL-metionina aumenta a porcentagem de saturação de oxigênio no sangue, e níveis de $0.153 \%$ de lisina na dieta pode favorecer o sistema imunológico de codornas japonesas na fase de posição, evitando o aparecimento de patologias que afectam os sistemas de produção.

Palavras-chave: Perfis metabólicos, aminoácidos, metionina, lisina, ovo.

\section{INTRODUCCIÓN}

La codorniz es un ave pequeña que pesa aproximadamente 170 gramos la hembra y 150 gramos el macho en su edad adulta. Es precoz, alcanzado la madurez sexual en poco tiempo (35 a 42 días) y tiene una extraordinaria facultad para reproducirse, es rústica y fácil de criar. En Colombia se han reportado más de cinco especies de codorniz, pero sólo tiene importancia económica la Coturnix coturnix japonica originaria de China y Japón. La explotación coturnícola ofrece 
grandes posibilidades como son: producción de carne y huevos, aprovechamiento de subproductos (pluma y codornaza) y la comercialización de hembras de reemplazo (Tobón et al., 2009).

Hurtado et al., (2010) expresan que el promedio de peso del huevo es de 10.9 gramos, alrededor de un $8 \%$ del peso corporal de la codorniz hembra. Los polluelos pesan de 6-7 $\mathrm{g}$ al nacer y son de color café con rayas amarillas. Los cascarones son frágiles, por lo cual hay que manejarlos con mucho cuidado. Las investigaciones indican que por lo general agrupar un solo macho con dos o tres hembras resulta en alta fertilidad. Cuando la codorniz se mantiene en corrales de colonias, la relación de un macho a tres hembras es suficiente y reduce las peleas entre machos; los apareamientos en pares en jaulas individuales también dan buena fertilidad.

Atendiendo las necesidades nutricionales en las codornices, se logra que las aves expresen su máximo potencial genético para la producción de huevos. Se entiende que todo esto debe ser dado en condiciones ambientales óptimas que influyan en la buena salud de un plantel. Un exceso o déficit de un aminoácido esencial en la dieta, afectará directamente la producción, y por tanto afectará la fisiología de los animales en lo relacionado a su hematología y química sanguínea, que mediante exámenes de estos factores, sus resultados pueden aportar elementos de juicio para el manejo sanitario o nutricional de las codornices y así se podrá realizar una corrección adecuada en pro de mejorar el bienestar animal y aumentar los picos de producción (Rostagno et al., 2005).

Las variables ambientales, como la temperatura y humedad relativa, interfieren con el desempeño productivo de las aves, así como también lo hace la deficiencia o exceso de algunos aminoácidos en la dieta. En términos de bienestar las aves responden a los cambios fisiológicos elevando su ritmo cardiaco, aumentando la liberación de corticosterona y catecolaminas, y en algunos casos presentando inmunosupresión (Nordi et al., 2007; Rosa et al., 2011). Se ha demostrado que el sistema circulatorio es particularmente sensible a los cambios de temperatura y es 
un indicador importante de respuestas fisiológicas de las aves a los factores de estrés (Borges et al., 2003).

Según Vega y Figueredo, (2005) los análisis complementarios de diagnóstico, entre los que ocupa un lugar fundamental la bioquímica sanguínea, aportan un gran conocimiento de la variación fisiológica de las aves, así como de las potenciales alteraciones inducidas por otros factores que provocan enfermedades patológicas sanguíneas, por lo tanto, para establecer los intervalos de referencia hemáticos y bioquímicos se necesita de animales clínicamente sanos. Este criterio incluye especie, edad, sexo, estado productivo, medicamentos aplicados, sitio de toma de la muestra y condiciones de su almacenamiento, entre otros, por lo tanto, los intervalos de referencia deben ser validados para cada técnica que se utilice en el laboratorio. La hematología constituye una herramienta fundamental en las evaluaciones toxicológicas y ecotoxicológicas. Estas pruebas son un requisito que exigen los organismos regulatorios internacionales para obtener la autorización y comercialización de nuevos productos.

Debido a que en nuestro medio no se cuenta con valores de referencia de hematología y química sanguínea propios de nuestra región, con este trabajo se pretende aportar datos básicos e imprescindibles para el manejo clínico y nutricional de la codorniz japonesa (Coturnix coturnix japonica) en la ciudad de Villavicencio. Los resultados obtenidos servirán de guía en posteriores investigaciones institucionales o regionales, a la vez podrán ser utilizados como ayuda para afrontar diversos problemas productivos como calidad del huevo, ya que con estos exámenes podemos medir deficiencias o excesos de algunos minerales esenciales para su producción. Con base a experiencias de Cando, (2010) este trabajo se enfocó en evaluar los efectos de diferentes niveles de metionina y lisina sobre los valores medios de hematología y química sanguínea para Codornices japonesas en fase de postura (Coturnix coturnix japonica).

Según Ashraful, (2013) la hematología sanguínea es importante para descubrir cualquier enfermedad de las aves; estos exámenes incluyen hemograma, bioquímica y pruebas serológicas. En el hemograma se miden parámetros 
comunes como porcentaje de hemoglobina y conteo de eritrocitos y leucocitos. En el estudio bioquímico se determinan algunos parámetros como el calcio, la glucosa y el colesterol. Para pruebas serológicas se estiman entre otras los niveles de albúmina y proteínas totales, tal como se puede apreciar en la Tabla 1.

Tabla1. Hematología sanguínea de la codorniz

\begin{tabular}{cccccc}
\hline Parámetro & Rango $(\%)$ & Bioquímica & Rango $(\mathbf{m g} / \mathbf{d l})$ & Serología & Rango (mg/dl) \\
\hline Hemoglobina & $13.3 \pm 0.22$ & Calcio & $10.06 \pm 0.42$ & Albúmina & $15.549 \pm 141.85$ \\
Linfocitos & $64.30 \pm 3.47$ & Glucosa & $193 \pm 4.42$ & Globulina & $14.915 .50 \pm 128.29$ \\
Monocitos & $3.60 \pm 0.97$ & Colesterol & $144 \pm 2.58$ & $\begin{array}{c}\text { Proteínas } \\
\text { Totales }\end{array}$ & $30.464 .50 \pm 238.50$ \\
\hline
\end{tabular}

Fuente: Ashraful, (2013).

En anfibios, reptiles y aves se han considerado cinco líneas de células blancas denominadas heterófilos, eosinófilos, basófilos, linfocitos y monocitos; sin embargo hay quienes incluyen dentro de la clasificación neutrófilos caracterizados como células que no tienen núcleo segmentado, diferentes de los heterófilos, solo por la coloración de sus gránulos citoplasmáticos (Hernández, 2006).

Según Gálvez et al., (2009) afirman que en hematología aviar se utiliza el EDTA como anticoagulante, afectando poco la morfología celular. No obstante, en aves muy pequeñas o muestras insuficientes el EDTA produce hemólisis y en estos casos es preferible el envío de capilares heparinizados junto con una extensión de sangre para el estudio hematológico (Tabla 2). Según Hernández, (2006) los trombocitos presentan formas variadas dependiendo de la especie; sin embargo son similares en cuanto a la presencia de núcleo voluminoso y denso parecido al núcleo de los linfocitos, el citoplasma aparece de color gris pálido y también muestra tendencia a la agregación. En el hemograma se cuantifica el número de plaquetas y el volumen plaquetario medio (VPM). El VPM proporciona información sobre el tamaño de las plaquetas; la serie plaquetaria compuesta por plaquetas 0 trombocitos, se relaciona con los procesos de coagulación sanguínea (Cando, 2010). 
Tabla 2. Morfología de las células sanguíneas de las aves

\begin{tabular}{cl}
\hline Eritrocitos & $\begin{array}{l}\text { La célula madura es oval o elíptica, con citoplasma anaranjado, } \\
\text { núcleo oval de color púrpura situado centralmente. Las formas } \\
\text { inmaduras son más redondeadas y con citoplasma azulado (basófilo). } \\
\text { En aves sanas son frecuentes formas juveniles. }\end{array}$ \\
Heterófilos & $\begin{array}{l}\text { Gránulos alargados o redondeados eosinófilos. Citoplasma incoloro. } \\
\text { Gránulos redondos, eosinófilos y refráctiles. Citoplasma azulado, }\end{array}$ \\
Eosinófilos & $\begin{array}{l}\text { ligeramente granulado. Las rapaces sanas poseen un número } \\
\text { elevado de eosinófilos }\end{array}$ \\
Célula de pequeño tamaño con gránulos intensamente basófilos.
\end{tabular}

Fuente: Gálvez et al., (2009).

En el examen de química sanguínea se puede evaluar: proteínas totales, albúminas, globulinas, colesterol, glucosa, creatinina, urea, calcio, fósforo, Según Vieites et al., (2011) las proteínas del plasma son responsables de mantener el equilibrio osmótico coloidal del plasma, y por tanto una presión arterial dentro de límites normales. Además, ayudan a regular el equilibrio ácido-base de la sangre y participar en el transporte de nutrientes (calcio, fosforo, hierro, cobre, lípidos, vitaminas solubles en grasa y aminoácidos), hormonas, colesterol, bilirrubina y otras sustancias. Las proteínas sanguíneas son muy importantes en el mantenimiento de la homeostasis metabólica en las aves, promueven una presión osmótica adecuada para prevenir la extravasación de sangre y mantener un $\mathrm{pH}$ apropiado; mediante un efecto buffer, se puede ver un incremento verdadero en anormalidades inflamatorias y en hemoconcentración por deshidratación; las fracciones proteicas son albúmina y globulina, la albúmina sirve como una proteína de reserva y como transportador de otras moléculas y las globulinas incluyen las proteínas inflamatorias, proteínas de coagulación e inmunoglobulinas; 
aunque no está bien documentado en aves, se espera que la relación albúminaglobulina esté incrementada en muchas anomalías hepáticas y en enfermedades desgastantes como el ayuno (Franco et al., 2009).

Según Cando, (2010) la mayoría de los animales pueden tener niveles elevados de colesterol después de alimentarse con alimentos ricos en grasa, también en disfunción hepática incluyendo la obstrucción del conducto biliar, porque la destrucción de las células hepáticas trae como consecuencia una disminución en la actividad metabólica del hígado y se reduce más la degradación del colesterol que la síntesis, por lo que los niveles en sangre aumentan. En hipotiroidismo los niveles de colesterol aumentan porque la carencia de hormonas tiroideas reduce la actividad metabólica de las células hepáticas, así como también de las células de otras partes del organismo. También aumentan los niveles de colesterol en diabetes mellitus y en nefrosis, pudiéndose presentarse un ligero incremento con infarto en el miocardio.

Según Franco et al., (2009) el aumento de la concentración de creatinina en aves está asociado con la alimentación a base de dietas de alto contenido proteico (como alimento para perros), septicemias, traumas renales y drogas nefrotóxicas. Un incremento en los niveles de urea puede ocurrir en todas las condiciones que causen bajo flujo de orina como en deshidrataciones u obstrucción uretral bilateral.

El calcio se puede encontrar en las proteínas plasmáticas (albúmina, globulina), en otros compuestos orgánicos y también en fosfatos y aniones, el medio de su forma biodisponible es disociada. La concentración de calcio en la sangre se mantiene dentro de los límites por la acción de hormonas que controlan la absorción, excreción y el metabolismo óseo, tales como la paratiroidea y tirocalcitonina. El calcio en plasma es esencial para la coagulación de la sangre, permeabilidad de la membrana, la excitabilidad neuromuscular, transmisión de impulsos nerviosos y la activación de sistemas enzimáticos (Vieites et al., 2011).

El calcio y el fósforo son los principales minerales utilizados en el desarrollo de las aves de corral principalmente relacionados con el metabolismo, en particular en la 
formación de hueso, con 99\% del calcio corporal total, y 80 a $85 \%$ de fósforo están presentes en los huesos (Vargas et al., 2004). El aumento del fósforo puede ser visto en casos graves de daño renal debido a hipervitaminosis por vitamina $D$, hiperparatiroidismo secundario nutricional e hipoparatiroidismo, falsos aumentos pueden ocurrir en muestras hemolizadas (Franco et al., 2009).

Los aminoácidos tienen un grupo amino que está unido al carbono contiguo al grupo carboxilo, diferenciándose por sus cadenas laterales. Son 20 los $\alpha-$ aminoácidos: alanina, arginina, asparagina, ácido aspártico, cisteína, glutamina, ácido glutámico, glicina, histidina, isoleucina, leucina, lisina, metionina, fenilalanina, prolina, serina, treonina, triptófano, tirosina, valina, Estos son los aminoácidos que se incorporan a las proteínas para formarlas, otros al encontrarse en exceso son precursores, la metionina puede formar cistina cuando la primera se encuentra en exceso; los aminoácidos a su vez se clasifican en no esenciales y esenciales (Mathews et al., 2002).

La metionina es el primer aminoácido limitante para las aves, por ser donadora de radicales metil necesarios en la biosíntesis de colina, creatinina, poliaminas, epinefrina y melatonina que son componentes corporales fundamentales para el crecimiento normal de los animales (Castro et al., 2011). El cuerpo puede transformar la metionina a cistina, este catabolismo puede ser útil en los momentos en que hay excesos de metionina en el organismo y superar las deficiencias de cistina. La cistina participa en la estructura de muchas proteínas como la insulina, las inmunoglobulinas y la queratina, interconectando las cadenas polipeptídicas por puentes disulfuro (Corrêa et al., 2006).

La lisina es considerada un aminoácido esencial porque es sintetizada en los tejidos en cantidades insuficientes para atender las necesidades de las aves, obligando al uso de lisina preformada presente en la proteína intacta del alimento o en fuentes sintética como L-lisina HCL. Este aminoácido es considerado como el patrón para determinar los requerimientos de los demás aminoácidos esenciales a la hora de formular una dieta utilizando el concepto de proteína ideal, lo que corresponde al perfil teóricamente exacto de aminoácidos digestibles en la dieta, 
que contribuye a la reducción de nitrógeno excretado y a mejorar el desempeño zootécnico de las aves (Moura et al., 2007). Según Ribeiro et al., (2003) la lisina también juega un papel importante en el cuerpo participando en la síntesis de la carnitina, que opera en el transporte de ácidos grasos para la $\beta$-oxidación en la mitocondria, la formación de la matriz ósea en animales jóvenes y en el crecimiento muscular.

\section{METODOLOGÍA}

La metodología propuesta correspondió a un proyecto de investigación aplicada, relacionado con la alimentación, nutrición y salud animal; el experimento se realizó en la Unidad de Codornices de la Granja Barcelona y en el laboratorio de la Clínica Veterinaria del programa de Medicina Veterinaria y Zootecnia perteneciente a la Universidad de los Llanos. Esta institución se encuentra a 465 msnm, con una humedad relativa del $85 \%$, temperatura promedio de $25.6^{\circ} \mathrm{C}$, y una precipitación anual entre 1830 y 3568 mm (Silva et al., 2013).

Se utilizaron 36 codornices japonesas (Coturnix coturnix japonica) en fase de postura con 45 días de edad, en un diseño experimental completamente al azar con tres tratamientos, cuatro repeticiones y tres aves por unidad experimental, las cuales fueron alojadas en un galpón cerrado con techo de zinc, ubicadas en baterías de jaulas, elaboradas con alambre galvanizado, que constan de cinco pisos con tres divisiones, dotados de comederos convencionales y bebederos automáticos.

Las raciones eran granuladas y estaban constituidas por maíz, torta de soya, aceite, suplementos de vitamina y minerales, sal, fosfato bicálcico, carbonato de calcio y material inerte (Tabla 3). El suministro de ración en los comederos fue realizado dos veces al día (7:00 am y 4:00 pm). Estas dietas estaban balanceadas para suplir los requerimientos de fósforo disponible, calcio, sodio, treonina, energía metabolizable y proteína cruda recomendados por Rostagno et al. (2005).

Los tratamientos estaban constituidos por raciones isoprotéicas e isoenergéticas (Tabla 3) con dos niveles de suplementación de L-lisina- $\mathrm{HCl}(0.00$ y $0.153 \%)$ 
resultando en dos dietas con 0.917 y $1,037 \%$ de lisina digestible para codornices japonesas en fase de postura, la lisina sintética estaba incluida en sustitución al material inerte de la dieta. con dos niveles de suplementación de DL-metionina (0.00 y $0.121 \%$ ) resultando en dietas con 0.274 y $0.394 \%$ de metionina digestible para codornices japonesas en fase de postura, quedando tres tratamientos: dieta basal, ración con lisina y ración con metionina.

Tabla 3. Ración experimental para codornices japonesas en fase de postura y composición nutricional

\begin{tabular}{|c|c|c|c|c|c|c|c|}
\hline Ingredientes & $\begin{array}{c}\text { Dieta Basal } \\
100 k\end{array}$ & $\begin{array}{c}\text { Ración } \\
\text { con } \\
\text { Lisina }\end{array}$ & $\begin{array}{c}\text { Ración } \\
\text { con } \\
\text { Metionina }\end{array}$ & $\begin{array}{l}\text { Nutrientes } \\
(\%)\end{array}$ & Testigo & $\begin{array}{c}\text { Ración } \\
\text { con } \\
\text { Lisina }\end{array}$ & $\begin{array}{l}\text { Ración } \\
\text { con } \\
\text { Metionina }\end{array}$ \\
\hline Maíz & 56.772 & 56.772 & 56.772 & $\begin{array}{c}\text { Proteína } \\
\text { bruta }\end{array}$ & 19.61 & 19.61 & 19.61 \\
\hline Torta de soya & 31.98 & 31.98 & 31.98 & $\begin{array}{c}\text { Fósforo } \\
\text { disponible }\end{array}$ & 0.304 & 0.304 & 0.304 \\
\hline $\begin{array}{l}\text { Fosfato } \\
\text { Bicálcico }\end{array}$ & 1.09 & 1.09 & 1.09 & Sodio & 0.196 & 0.196 & 0.196 \\
\hline $\begin{array}{l}\text { Carbonato de } \\
\text { calcio }\end{array}$ & 6.664 & 6.664 & 6.664 & Calcio & 2.50 & 2.50 & 2.50 \\
\hline Aceite vegetal & 1.61 & 1.61 & 1.61 & Fibra cruda & 2.7 & 2.7 & 2.7 \\
\hline Vitamix & 0.5 & 0.5 & 0.5 & Lisina & 0.917 & 1.037 & 0.917 \\
\hline Sal & 0.45 & 0.45 & 0.45 & Metionina & 0.274 & 0.274 & 0.394 \\
\hline L- Lisina HCL & 0.00 & 0.153 & 0.00 & Treonina & 0.643 & 0.643 & 0.643 \\
\hline DL- Metionina & 0.00 & 0.00 & 0.121 & $\begin{array}{c}\text { Energía } \\
\text { Metaboliza } \\
\text { ble kcal/kg }\end{array}$ & 2791 & 2791 & 2791 \\
\hline Material inerte & 0.934 & 0.934 & 0.934 & & & & \\
\hline
\end{tabular}

\section{Toma de muestras}

La técnica utilizada fue la obtención a través de la vena yugular (en el lado derecho del cuello del ave) debido a su fácil localización; la aguja se alinea con la vena yugular teniendo la precaución de introducirla primero dentro de la piel y luego en la vena, el bisel hacia arriba dirigiéndose hacia la cabeza para aprovechar la sangre que corre de regreso hacia el corazón, lo cual facilita la extracción de la sangre en la jeringa; si la guja se encuentra dentro de la vena, la jeringa se llena de sangre con un mínimo jalón al succionarla; si el embolo se jala con demasiada fuerza, se crea suficiente presión negativa haciendo que la vena 
sufra un colapso y pare la entrada de la sangre en la aguja. La sangre fue extraída lentamente hacia la jeringa para evitar dañar las células sanguíneas, luego se extrajo la aguja de la vena y se realizó presión con el dedo sobre el sitio de la venopunción para promover rápida coagulación (Grieve, 2013).

Las muestras de sangre se almacenaron en un tubo vial con anticoagulante (EDTA), para obtener los parámetros hemáticos éstas fueron procesadas en el Laboratorio Clínico Veterinario de la Universidad de Los llanos y las de química sanguínea se procesaron en un analizador de sangre portátil EPOC ${ }^{\circledR}$ para uso Veterinario.

El método estadístico aplicado en este experimento fue bajo un diseño completamente al azar realizando un análisis de varianza, media y coeficiente de variación, mediante en el software de análisis estadístico Statistical Analysis System, (2000), para cada parámetro evaluado como: Hematología sanguínea. 1Hematocrito, conteo total de: eritrocitos, hemoglobina, reticulositos, linfocitos y recuento diferencial de leucocitos e índice eritrocitario. 2-Química sanguínea: glucosa, lactosa, calcio, potasio, sodio y gasometría venosa.

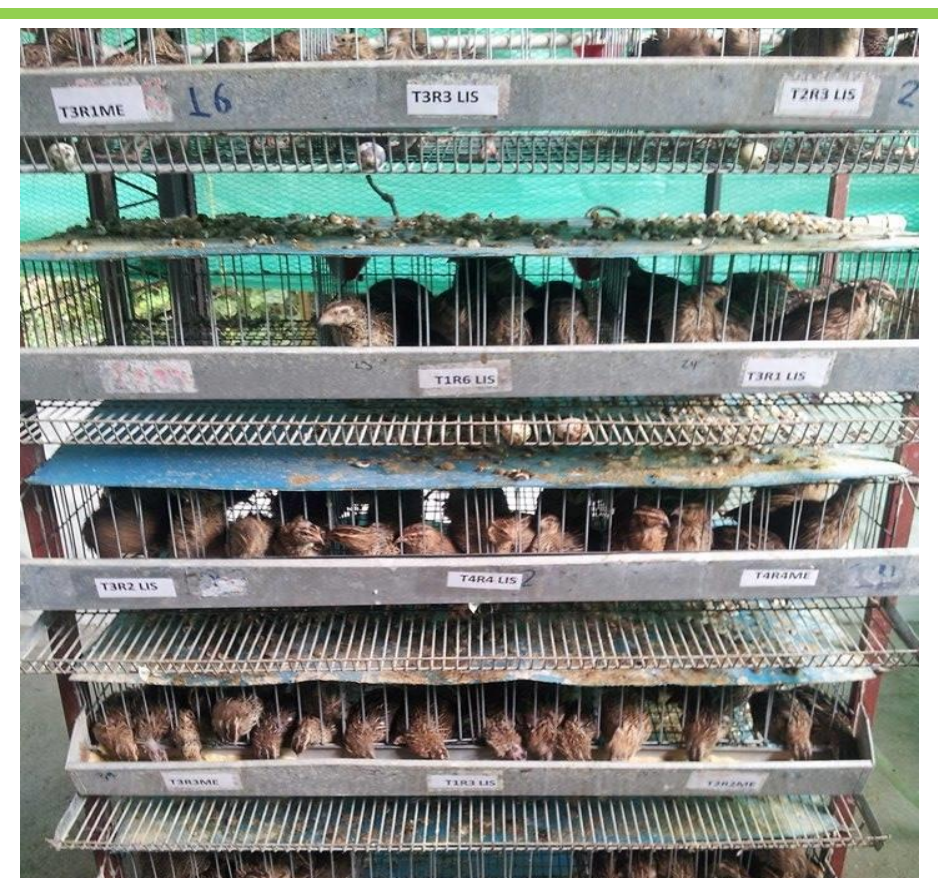

Fotografía 1. Distribución de las unidades experimentales 


\section{RESULTADOS Y DISCUSIÓN}

\section{Hematología}

El comportamiento de los parámetros hematológicos de las codornices japonesas (Coturnix coturnix japonica) alimentadas con tres tratamientos diferentes (dieta basal, ración con lisina y con metionina) indicaron que no fueron afectados $(P>0.05)$ excepto para el recuento diferencial de leucocitos, aumentándose $(\mathrm{P}<0.05)$ su número por el uso de lisina como suplemento en ración (Tabla 4 y Gráfica 1).

Tabla 4. Parámetros de hematología en sangre de codornices japonesas suplementadas con aminoácidos sintéticos

\begin{tabular}{ccccccc}
\hline Parámetro & $\begin{array}{c}\text { Ración } \\
\text { Basal }\end{array}$ & Lisina & Metionina & Promedio & $\mathbf{P}^{*}$ & CV \\
\hline Erit $\left(0^{6} / \mathrm{mm}^{3}\right)$ & 2.475 & 3.063 & 3.313 & 2.95 & $\mathrm{NS}$ & 25.41 \\
Hgb $(\mathrm{g} / \mathrm{dl})$ & 8.88 & 9.28 & 9.25 & 9.13 & $\mathrm{NS}$ & 8.75 \\
HTC $(\%)$ & 40.25 & 38.25 & 38.75 & 39.08 & $\mathrm{NS}$ & 12.10 \\
VCM (fl) & 164.25 & 114.13 & 126.00 & 134.79 & $\mathrm{NS}$ & 25.91 \\
Tromb $\left(10^{3} / \mathrm{mm}^{3}\right)$ & 16.00 & 18.88 & 19.50 & 18.17 & $\mathrm{NS}$ & 18.62 \\
Leuc $\left(10^{3} / \mathrm{mm}^{3}\right)$ & $106.75^{\mathrm{b}}$ & $122.00^{\mathrm{a}}$ & $96.00^{\mathrm{b}}$ & 108.25 & $\mathrm{~S}$ & 11.13 \\
Het $\left(10^{3} / \mathrm{mm}^{3}\right)$ & 55.7 & 61.3 & 53.1 & 56.7 & $\mathrm{NS}$ & 15.20 \\
Linf $\left(10^{3} / \mathrm{mm}^{3}\right)$ & 34.4 & 51.5 & 40.6 & 42.17 & $\mathrm{NS}$ & 21.98 \\
Eos $\left(10^{3} / \mathrm{mm}^{3}\right)$ & 7.7 & 8.2 & 6.0 & 7.3 & $\mathrm{NS}$ & 28.23 \\
Mon $\left(10^{3} / \mathrm{mm}^{3}\right)$ & 5.0 & 6.5 & 5.6 & 5.7 & NS & 18.62 \\
Bas $\left(10^{3} / \mathrm{mm}^{3}\right)$ & 2.4 & 2.7 & 2.2 & 2.43 & NS & 33.55 \\
\hline
\end{tabular}

Erit: Eritrocitos. Hgb: Hemoglobina. HTC: Hematocrito. VCM: Volumen corpuscular medio. Tromb: Trombocitos. Leuc: Leucocitos. Het: Heterófilos. Linf: Linfocitos. Eos: Eosinófilos. Mon: Monocitos. Bas: Basófilos. ${ }^{*}$ S: no significativo. S: significativo. CV: Coeficiente de variación. Se aplicó la prueba de Tukey $(\mathrm{P}<0.05)$.

Los estudios hematológicos de las codornices son de interés veterinario y zootécnico, ya que a través de ellos se determina el estado nutricional y de salud de estas, y más aún, cuando los factores ambientales hacen que cada población presente sus propios parámetros según el lugar, y tipo de manejo. Corredor y 
Rodríguez, (2010) indican que al manejar parámetros hemáticos y séricos de cualquier especie, se deben considerar que los métodos de captura, restricción (física y química) y de obtención de muestras, tienen efectos sobre los valores de estos parámetros. Igual influencia puede tener el tiempo de persecución para la toma, la temperatura ambiental, el comportamiento del animal, factores que deben tenerse en cuenta al interpretar los resultados.

Se puede observar aumento de los leucocitos $(\mathrm{P}<0.05)$, principalmente en los heterófilos para la ración basal, lisina y metionina $\left(55.7,61.3\right.$ y $53.1 \times 10^{3} / \mathrm{mm}^{3}$ respectivamente), estos valores son mayores al compararlos con estudios realizados por Shivazad et al., (2013) quienes obtuvieron $20.25 \%$ con $1.0 \%$ de lisina en dietas para codornices, y con los de Bouyeh, (2012) quien reportó $34.75 \%$ de heterófilos en pollos de engorde. Sandoval et al., (2003) determinaron un aumento en heterófilos/linfocitos $(\mathrm{H} / \mathrm{L})$ y en el índice morfométrico bursal, los cuales fueron catalogados como indicadores de estrés crónico en pollos de engorde, estando asociados a situaciones en que las aves sufren de manera intensa estrés en breves lapsos de tiempo, por ejemplo en el momento de tomar las muestras sanguíneas, produciendo una leucocitosis fisiológica, sin que esté asociado a un proceso patológico, también se puede presentar liberación de epinefrina al torrente circulatorio manifestando excitación, temor, dolor y crisis convulsivas. Esta liberación aumenta el flujo sanguíneo y provoca heterofilia a partir del compartimiento marginal (Adeyemo et al., 2010; Sandoval et al., 2003).

El conteo de eosinófilos y basófilos fue similar para todos los tratamientos $(P>0.05)\left(7.3 \pm 0.56 \times 10^{3} / \mathrm{mm}^{3}\right.$ y $\left.2.43 \times 10^{3} / \mathrm{mm}^{3}\right)$, resultados que concuerdan con los de Nordi et al., (2007) y con los de Aengwanich y Chinrasri, (2003) quienes trabajaron con codornices japonesas alojadas en jaulas.

Según Gálvez et al., (2009) hay cinco tipos de células blancas en aves: 1heterófilos, eosinófilos y basófilos son conocidos como granulocitos por que poseen gránulos en su citoplasma; muchos granulocitos aviares poseen un núcleo polimórfico semejante a los granulocitos mamíferos; todas estas células se producen en la médula ósea y, 2- linfocitos y monocitos, conocidos como 
leucocitos mononucleares, estos últimos son semejantes a los de los mamíferos y se pueden diferenciar de otros leucocitos, tal como linfocitos, por su citoplasma más abundante y algunas veces la presencia de vacuolas citoplasmáticas. Estos dos tipos de células tienen un sólo núcleo sin gránulos en su citoplasma. La variabilidad en las cuentas leucocitarias puede ocurrir debido al método utilizado, colección de la muestra y preparación, así como la utilización correcta de parámetros como el tiempo y la temperatura.

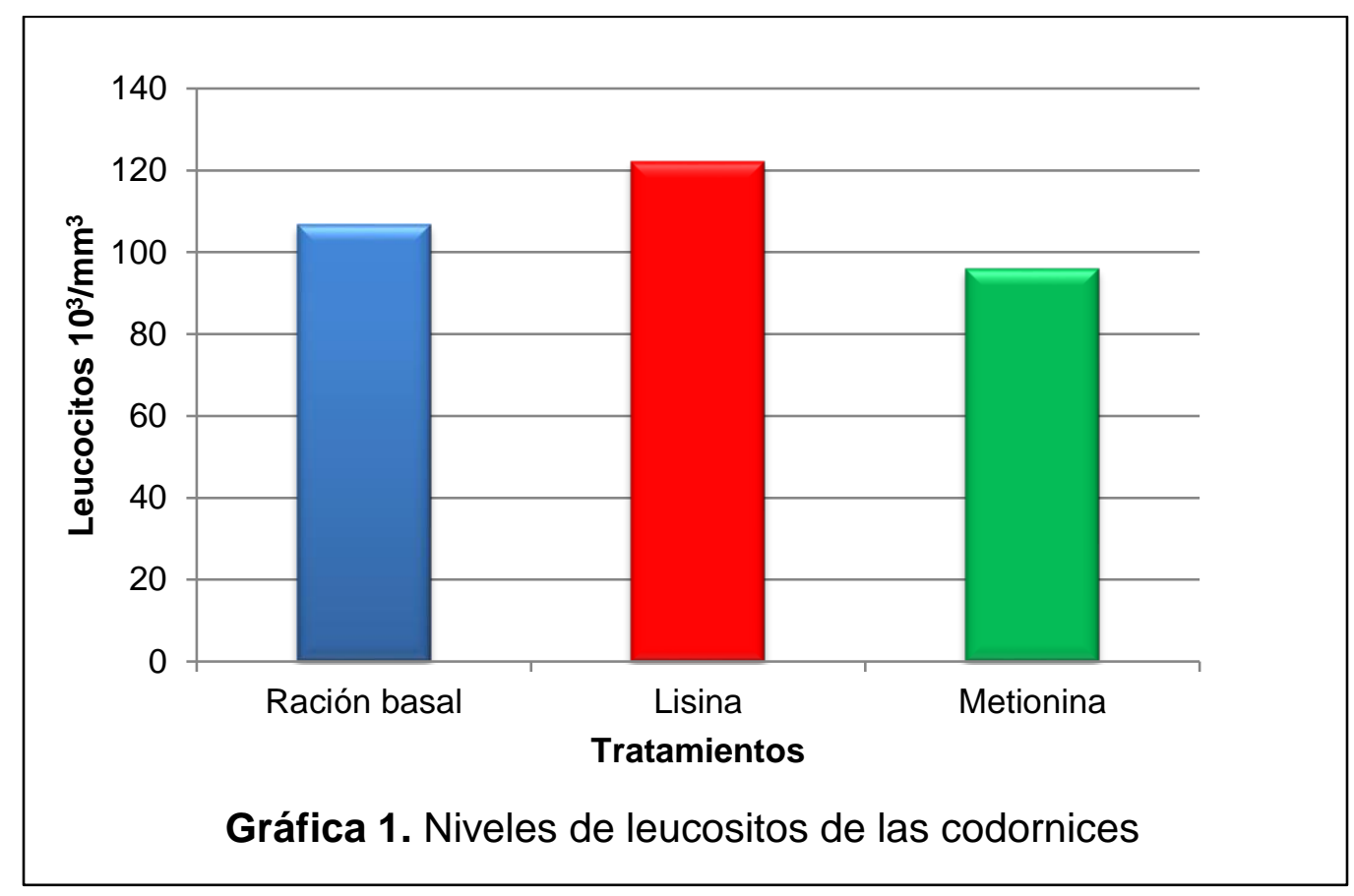

La concentración de eritrocitos $\left(2.95 \pm 0.054 \times 10^{6} / \mathrm{mm}^{3}\right)$ fue similar en los tres tratamientos $(P>0.05$ ) (Tabla 4) concordado con los estudios realizados por Rosa et al., (2011) quienes determinaron valores hematológicos y de proteína total en codornices a $25.5^{\circ} \mathrm{C}$. Según Hernández, (2006) los eritrocitos son nucleados, biconvexos y ovales, la morfología difiere de los mamíferos por su forma ovalada y presencia de núcleo en las células maduras, el cual es de forma oval o redondo en posición central con cromatina condensada, siendo abundante en el citoplasma. Entre las funciones de los eritrocitos está el transporte de hemoglobina llevando oxígeno desde los pulmones a los tejidos, intervienen en el transporte de anhídrido carbónico y participan en la regulación del pH (Andrade, 2009). 
Los valores de hemoglobina $(9.13 \mathrm{~g} / \mathrm{dl})$ (Tabla 4) fueron similares $(P>0.05)$ entre tratamientos, siendo muy semejantes a los encontrados por Ocampo et al., (2012) en un estudio con pollos de engorde de la línea Coob-Vantres, bajo las condiciones estándares de alimentación y manejo de cada línea en granjas tecnificadas, en altitudes menores de $500 \mathrm{msnm}$. La hemoglobina es una proteína globular, que está presente en altas concentraciones en los glóbulos rojos y se encarga del transporte de $\mathrm{O}_{2}$ del aparato respiratorio hacia los tejidos periféricos; y del transporte de $\mathrm{CO}_{2}$ y protones $\left(\mathrm{H}^{+}\right)$de los tejidos periféricos hasta los pulmones para ser excretados (Brandan et al., 2008).

El hematocrito $(\mathrm{HCT})(39.08 \pm 0.7 \%)$ (Tabla 4), tampoco muestra variación ( $P>0.05$ ) siendo similar al resultado obtenido por Nordi et al., (2007) en codornices confinadas en jaulas de $45 \times 60 \times 26.5 \mathrm{~cm}$, cuyo trabajo tenía el propósito de diagnosticar el grado de bienestar de codornices japonesas en dos sistemas de crianza. El hematocrito es un factor clave que influye en el flujo de la sangre y la distribución de ésta dentro de los diferentes lechos vasculares de la circulación, por lo tanto, la regulación de HCT es de importancia crítica en la eficacia final de la perfusión y la oxigenación de los tejidos Andrewartha et al., (2011). En la medición del volumen corpuscular medio (VCM) $(134.79 \pm 8.64 \mathrm{fl})$ no se observaron cambios $(P>0.05)$ siendo estos valores similares a los encontrados por Islam et al., (2004) en pollos de línea Assil de tres meses de edad, en Bangladés.

Las dietas evaluadas no afectaron $(P>0.05)$ el conteo de trombocitos en sangre (18.17 x 103/ $\left.\mathrm{mm}^{3}\right)$, según Claver, (2005) estas células tienen una función parecida a las plaquetas de mamíferos en los procesos hemostáticos, donde se adhieren entre sí y agregan en el sitio de una injuria vascular formando un tapón hemostático, sin embargo, a diferencia de las plaquetas, no sólo poseen núcleo sino también una variada gama de organelos, entre los cuales se destaca un desarrollado lisosoma; no hay megacariocitos en la médula ósea de las aves por lo que se originan de precursores nucleados. Los trombocitos son el tercer tipo de células que más se encuentra en la sangre aviar y son participantes activos en la coagulación, además, tienen la habilidad de fagocitar material extraño (bacterias) y 
ser capaces de llevar oxígeno como los eritrocitos si una condición anémica extrema así lo exige (Gálvez et al., 2009).

\section{Química sanguínea}

En la medición correspondiente a química sanguínea (Tabla 5) los niveles de glucosa no se afectaron por los tratamientos $(P>0.05)$ concordando con los obtenidos por Bardai et al., (2005) de $293.4 \pm 1.0 \mathrm{mg} / \mathrm{dL}$ en codornices japonesas. El lactato tampoco cambió $(P>0.05)$, similar a los resultados reportados por Butkauskas et al., (2006) quienes trabajaron con lactato en codornices japonesas (Coturnix coturnix japonica), siendo este componente el resultado de la reducción del piruvato al ser este catalizado por la enzima lactato deshidrogenasa, así pues al haber liberación de lactato en la sangre, este puede ser captado con facilidad por el corazón que lo oxida como combustible; parte del lactato que se produce entra en el hígado en donde se oxida a piruvato, el cual participa en el proceso de gluconeogénesis para generar glucosa que se devuelve al torrente sanguíneo y se capta por el músculo para generar las reservas de glucógeno (Mathews et al., 2002).

Tabla 5. Parámetros de química en sangre de Codornices Japonesas suplementadas con aminoácidos sintéticos

\begin{tabular}{ccccccc}
\hline Parámetro & $\begin{array}{c}\text { Ración } \\
\text { Basal }\end{array}$ & Lisina & Metionina & Promedio & $\mathbf{P}^{*}$ & CV \\
\hline Glucosa $(\mathrm{mg} / \mathrm{dl})$ & 287.50 & 297.00 & 307.75 & 297.42 & $\mathrm{NS}$ & 10.01 \\
Lactato $(\mathrm{mmol} / \mathrm{L})$ & 3.73 & 3.29 & 3.77 & 3.59 & $\mathrm{NS}$ & 11.56 \\
$\mathrm{Ca}(\mathrm{mmol} / \mathrm{L})$ & 0.51 & 0.54 & 0.65 & 0.56 & $\mathrm{NS}$ & 17.77 \\
$\mathrm{~K}(\mathrm{mmol} / \mathrm{L})$ & 3.95 & 2.83 & 3.00 & 3.26 & $\mathrm{NS}$ & 24.76 \\
$\mathrm{Na}(\mathrm{mmol} / \mathrm{L})$ & 144.75 & 152.50 & 151.75 & 149.67 & $\mathrm{NS}$ & 7.79 \\
\hline
\end{tabular}

$\mathrm{Ca}$ : calcio. K: potasio. Na: sodio. ${ }^{*} \mathrm{NS}$ : no significativo. S: significativo. CV: Coeficiente de variación

Los tratamientos evaluados no causaron diferencias $(P>0.05)$ en los niveles de calcio en sangre (Tabla 5$)$, obteniendo resultados menores $(0.56 \mathrm{mmol} / \mathrm{L})$ a los a 
los de Babangida y Ubosi, (2005) (1.52 mmol/L). Los síntomas de la deficiencia de calcio causan cáscaras de huevo delgadas, pérdida del apetito, debilidad en las patas, fatiga y osteoporosis, de manera similar al caso de las gallinas, una deficiencia de éste mineral en la dieta de codornices causa disminución en la producción de huevos (Sultana et al., 2007). Cabe destacar que en ningún momento durante este estudio la población de codornices presento los síntomas anteriormente nombrados, ni hubo una disminución en su postura.

Los niveles de potasio y sodio (Tabla 5) observaron no cambió entre tratamientos ( $P>0.05)$, en promedio 3.26 y $149.67(\mathrm{mmol} / \mathrm{L})$, siendo estos valores similares a los obtenidos por Bardai et al., (2005) (3.29 $\pm 0.5 \mathrm{mmol} / \mathrm{L}$ y $144.4 \pm 3.6 \mathrm{mmol} / \mathrm{L})$. La importancia del potasio radica en que es el tercer elemento más abundante del cuerpo del animal y el principal catión intracelular, participa en los procesos para la homeostasis del cuerpo, como el equilibrio ácido-base, regulación de la presión osmótica, el desarrollo de los potenciales de membrana de las células (la transmisión nerviosa, la actividad muscular, la función cardíaca), la activación de numerosas enzimas intracelulares, y la absorción de glucosa y aminoácidos y de transporte (Oliveira et al., 2005). El sodio es el principal catión en el líquido extracelular y está estrechamente asociado con el cloruro y bicarbonato $\left(\mathrm{HCO}_{3}\right)$ en la regulación del equilibrio ácido-base, también es esencial para la síntesis de proteínas en los tejidos, reacciones enzimáticas y la presión osmótica (Zakaria et al., 2009).

\section{Gasometría venosa}

Los niveles de saturación venosa de oxígeno $\left(\mathrm{SvO}_{2}\right)$ en la ración basal fueron más bajos $(\mathrm{P}<0.05)$ respecto a la ración de lisina y de metionina (Tabla 6 y Gráfica 2), $50.23 ; 76.70$ y $81.20 \%$, respectivamente. La medición de la saturación venosa de oxígeno sirve para determinar la cantidad de oxígeno que retorna al corazón y los pulmones (Carrillo et al., 2007). La dietas evaluadas no afectaron ( $P>0.05)$ los niveles de bicarbonato $\left(\mathrm{HCO}_{3}\right)$, electrolito que es esencial en la unión del hierro a la transferrina para que éste sea transportado en la sangre; contribuye al mantenimiento del pH interno, también es de gran utilidad para la neutralización de 
protones a nivel sanguíneo, ya que el $\mathrm{HCO}_{3}$ es convertido en $\mathrm{CO}_{2}$, y cuando hay hidrogeniones en la orina, mediante su unión se produce ácido carbónico, y en presencia de la enzima anidrasa carbónica, se disocia en agua y $\mathrm{CO}_{2}$, que se difunde pasivamente hacia el interior de la célula tubular en donde es reconvertido en bicarbonato en presencia de la misma enzima, y devuelto a la circulación sanguínea (Diaz et al., 1997). Tampoco en la medición del pH (Tabla 6) se observaron diferencias $(P>0.05)$, resultados que son similares al obtenido por Gálvez et al., (2009), en pollos de engorde a 2.600 metros sobre el nivel del mar $(7.50 \pm 0.05$ vs 7.61$)$.

Tabla 6. Gasometría venosa de Codornices Japonesas suplementadas con aminoácidos sintéticos

\begin{tabular}{ccccccc}
\hline Parámetro & $\begin{array}{c}\text { Ración } \\
\text { Basal }\end{array}$ & Lisina & Metionina & Promedio & $\mathbf{P}^{*}$ & CV \\
\hline $\mathrm{HCO}_{3}{ }^{-}(\mathrm{mmHg})$ & 26.63 & 25.23 & 24.90 & 25.58 & $\mathrm{NS}$ & 20.77 \\
$\mathrm{SvO}_{2}(\%)$ & $50.23^{\mathrm{b}}$ & $81.20^{\mathrm{a}}$ & $76.70^{\mathrm{a}}$ & 69.38 & $\mathrm{~S}$ & 14.73 \\
$\mathrm{PvCO}_{2}(\mathrm{mmHg})$ & 41.33 & 36.10 & 35.95 & 37.79 & $\mathrm{NS}$ & 16.27 \\
$\mathrm{pH}$ & 7.33 & 7.45 & 7.61 & 7.46 & $\mathrm{NS}$ & 2.10 \\
\hline
\end{tabular}

$\mathrm{HCO}_{3}$ : Bicarbonato, $\mathrm{SvO}_{2}$ : saturación venosa de oxígeno. $\mathrm{PvCO}_{2}$ : Presión de dióxido de carbono en sangre venosa periférica. ${ }^{*} \mathrm{NS}$ : no significativo, S: significativo.CV: Coeficiente de variación. Letras distintas en la misma línea indican diferencia significativa por la prueba de Tukey $(P<0.05)$.

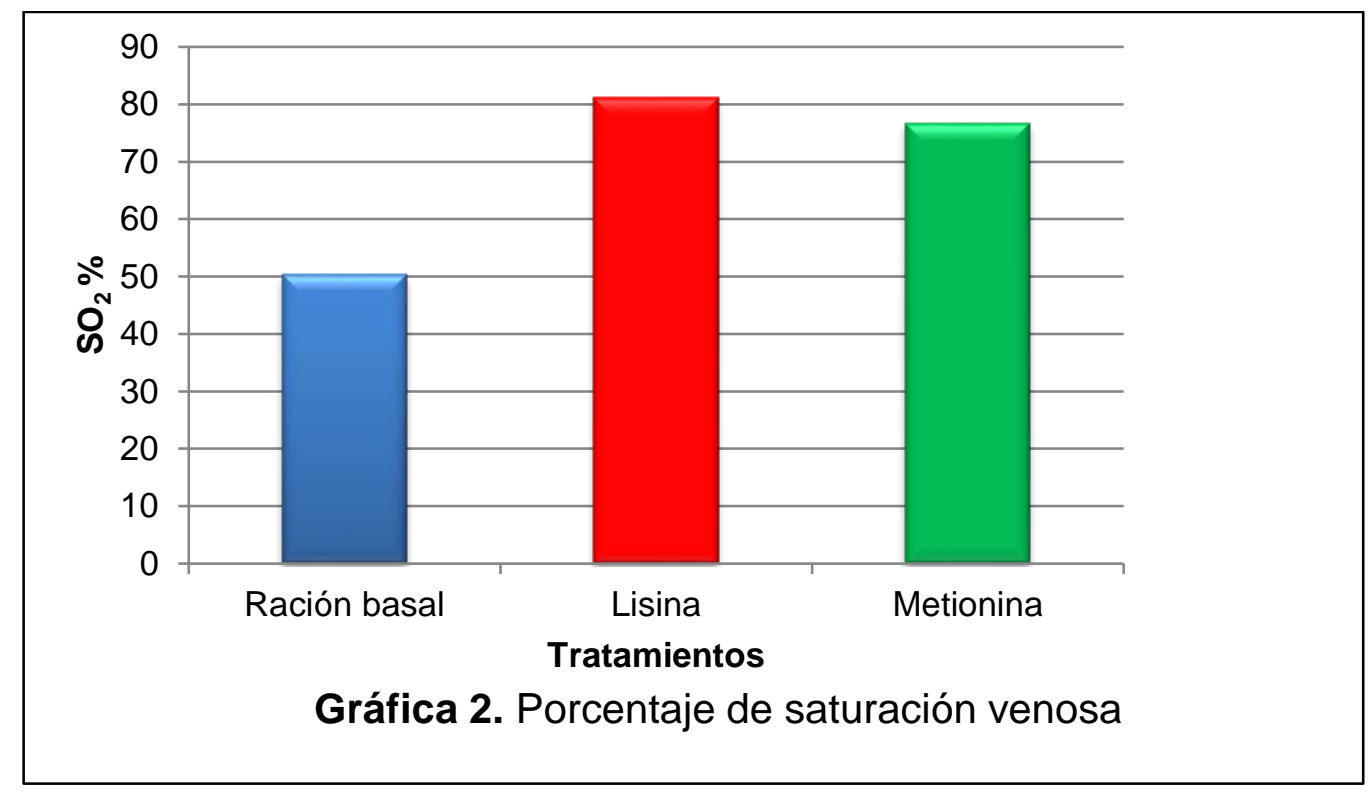




\section{CONCLUSIONES}

La suplementación con niveles de $0.153 \%$ de L-lisina-HCL en dietas para codornices japonesas en fase de postura, favorece el sistema inmune porque se incrementaron los leucocitos los cuales previenen la aparición de patologías que afectan los sistemas productivos. También la suplementación de aminoácidos sintéticos L-lisina-HCL y DL-metionina aumentan el porcentaje de saturación de oxígeno en sangre, lo cual es importante para el intercambio gaseoso en los tejidos.

\section{REFERENCIAS BIBLIOGRÁFICAS}

1. Adeyemo G., Ologhobo A., Adebiyi O. The effect of graded levels of dietary methionine on the hematology and serum biochemistry of broilers. International Journal of Poultry Science. 9, (2): 158-161. 2010.

2. Aengwanich W., Chinrasri O. Effect of dexamethasone on differential white blood cell counts and heterophil/lymphocyte ratio in Japanese quails (Coturnix coturnix japonica). Songklanakarin Journal of Science and Technology. 25, 183-189. 2003.

3. Andrewartha S.J., Tazawa H., Burggren W.W. Hematocrit and blood osmolality in developing chicken embryos (Gallus gallus): in vivo and in vitro regulation. Respiratory physiology \& neurobiology. 179, (2): 142-150. 2011.

4. Ashraful K. Blood chemistry analyses of Japanese quail (Coturnix coturnix Japonica). Scholarly Journal of agricultural Science. 3, (4): 132-136. 2013.

5. Babangida S., Ubosi C. Effects of varying dietary protein levels on the performance of laying Japanese quail (Coturrnix coturnnix japonica) in a semi-arid environment. J. Animal Production. 33, (1): 45-52. 2005.

6. Bardai G., Sunahara G., Spear P., Martel M., Gong P., Hawari J. Effects of dietary administration of CL-20 on Japanese quail Coturnix coturnix japonica. Archives of environmental contamination and toxicology. 49, (2): 215-222. 2005.

7. Borges S., Da Silva A.F., Ariki J., Hooge D., Cummings K. Dietary electrolyte balance for broiler chickens under moderately high ambient temperatures and relative humidities. Poultry Science. 82, (2): 301-308. 2003.

8. Bouyeh M. Effect of excess lysine and methionine on immune system and performance of broilers. Ann. Biol. Res. 3, 3218-3224. 2012.

9. Brandan N., Aguirre M., CE G. Hemoglobina. Catedra de Bioquímica - Facultad de Medicina. Universidad Nacional del Nordeste Argentina, 2008.

10. Butkauskas D., Sruoga A., Tubelytè-Kirdienè V., Mozalienè E., Paulauskas A. Enzyme polymorphism in two Japanese quail (Coturnix coturnix japonica) lines with different concentrations of plasma lactate. Acta Zoologica Lituanica. 16, (3): 177184. 2006.

11. Cando M., Química Sanguínea, 2010. Recuperado 29 de Septiembre 2013, Disponible En: http://www.actiweb.es/veterinarianorton/archivo9.pdf

12. Carrillo R., Núñez J.J., Carrillo J.R. Saturación venosa central. Conceptos actuales. Revista mexicana de anestesiología. 30. 165-171. 2007. 
13. Castro S.d.F., Alves B.D., Carrera J.C., Bertechini A.G., Borges L.S., Pinto A.A.J. Relação metionina e colina dietética sobre o desempenho de codornas japonesas (Coturnix coturnix japonica) em postura. Ciência Animal Brasileira. 12, (4): 635 641. 2011.

14. Claver J. El trombocito aviar. InVet. 7, (1): 139-146. 2005.

15. Corrêa G., Silva M., Corrêa A., Almeida V., Fontes D., Torres R., Dionello N., Freitas L., Ventura R., Paulo A. Exigência de metionina+ cistina total para codornas de corte em crescimento. Arq. Bras. Med. Vet. Zootec. 58, (3): 414-420. 2006.

16. Corredor J.R., Rodríguez J.A. Hematic and metabolic study of chiguiros (Hydrochaeris hydrochaeris) in captivity. Orinoquia. 14, 95-109. 2010.

17. Diaz J., Fernández M.T.z., Paredes F. Aspectos básicos de bioquímica clínica. Ediciones Díaz de Santos, Madrid, España. 1997.

18. Franco G., Hoyos L., Ramírez G.F., Correa A.M. Hallazgos hematológicos y química sanguínea en Amazona amazónica y Amazona ochrocephala cautivas de la reserva forestal Torre Cuatro. Boletín científico de museos de historia natural. 13, (2): 63-77. 2009.

19. Gálvez C., Ramírez G., Osorio J. El laboratorio clínico en hematología de aves exóticas. Biosalud. 8, 178-188. 2009.

20. Grieve D., Manera apropiada de extraer y de manipular las muestras de sangre y de suero en las aves. 2013. Recuperado 29 de Octubre 2013. Disponible En: http://www.microclin.com/archivos/toma de muestras de sangre y suero en av es Dr D Grieve.pdf

21. Hurtado V.L., Corredor L.F., Torres-Novoa D.M. Grano de soya integral cocido en la alimentación de codornices. Orinoquia. 14, 27-32. 2010.

22. Islam M., Lucky N., Islam M., Ahad A., Das B., Rahman M.M., Siddiui M. Haematological parameters of Fayoumi, Assil and local chickens reared in Sylhet region in Bangladesh. International Journal of Poultry Science. 3, (2): 144-147. 2004.

23. Mathews C., Holde K., Ahem K. Introducción a las proteínas: nivel primario de la estructura proteica. Capítulo 5. Metabolismo de los hidratos de carbonoll: biosíntesis. Capítulo 16. Bioquímica. Madrid, España. 1340 p. 2002.

24. Moura A.M.A.d., Soares R.d.T.R.N., Fonseca J.B., Vieira R.A.M., Couto H.P. Exigência de lisina para codornas japonesas (Coturnix japonica) na fase de cria. Ciênc. agrotec.,(Impr.). 31, (4): 1191-1196. 2007.

25. Nordi W., Yamashiro K., Klank M., Soares D., Dittrich R., Molento C., Diagnóstico de bem-estar de codornas japonesas utilizando a liberdade sanitária em dois sistemas de criação, 2007. Recuperado 11 de Septiembre 2013. Disponible En: http://www.abz.org.br/publicacoes-tecnicas/anais-zootec/artigoscientificos/bioclimatologia-ambiencia/3031-Diagnstico-bem-estar-codornasjaponesas-utilizando-liberdade-sanitria-dois-sistemas-criao.html

26. Ocampo J., Vásquez M., Cueva S., Ayón M., Lira B., Rodríguez J., Falcón N. Valores eritrocíticos, presión arterial pulmonar y peso del ventrículo derecho en pollos parrilleros de dos líneas comerciales bajo crianza intensiva a nivel del mar. Revista de Investigaciones Veterinarias del Perú. 23, (4): 406-413. 2012.

27. Oliveira J., Albino L., Rostagno H., Páez L., Carvalho D. Dietary levels of potassium for broiler chickens. Revista Brasileira de Ciência Avícola. 7, (1): 33-37. 2005. 
28. Ribeiro M.L.G., Silva J.d., Dantas M., Costa F.G.P., Oliveira S.d., Jordão Filho J., Silva E.d. Exigências nutricionais de lisina para codornas durante a fase de postura, em função do nível de proteína da ração. Revista Brasileira de Zootecnia. 32, (1): 156-161. 2003.

29. Rosa G.d.A.d., Sorbello L.A., Dittrich R.L., Moraes M.T.T.d., Oliveira E.G.d. Perfil hematológico de codornas japonesas (Coturnix japonica) sob estresse térmico. Ciência Rural. 41, 1605-1610. 2011.

30. Rostagno H., Albino L., Donzele J. Tabelas brasileiras para aves e suínos: composição de alimentos e exigências nutricionais. Viçosa. Minas Gerais, Brazil: Universidade Federal de Viçosa. 186 p. 2005.

31. Sandoval G.L., Terraes J., Revidatti J.C., Fernández R., Gauna C., G M. Hematocrito, relación heterófilo-linfocito e inmovilidad tónica en pollos con estrés psico-físico crónico criados en jaulas. Comunicaciones Científicas y Tecnológicas. 26, (1-3): 2003.

32. Shivazad M., Moravvej H., Zare-Shahneh A. Effect of dietary lysine on performance and immunity parameters of male and female Japanese quails. African Journal of Agricultural Research. 8, (1): 113-118. 2013.

33. Silva A., Zuluaga A., Roa M. Evaluación de la utilización de Cratylia argentea como suplemento en dietas para pollos de engorde. Revista Sistemas de Producción Agroecologicos. 4, (1): 144-152. 2013.

34. Statistical Analysis System I.S., User's Guide Statistics, 2000.

35. Sultana F., Islam M., Howlider M. Effect of dietary calcium sources and levels on egg production and egg shell quality of Japanese quail. International Journal of Poultry Science. 6, (2): 131-136. 2007.

36. Tobón F.A., Román M.O., Molina S., Bothert J.P. Determinación del perfil de ácidos grasos de la secreción de la glándula uropigial de la Coturnix coturnix japonica (codorniz doméstica). Revista Colombiana de Ciencias Pecuarias. 15, (2): 169-179. 2009.

37. Vargas J., Albino L.F.T., Rostagno H.S., Gomes P.C., Cupertino E.S., Carvalho D.C.O., Silva M., Pinto R. Níveis nutricionais de cálcio e de fósforo disponível para aves de reposição leves e semipesadas de 7 a 12 semanas de idade. Rev Bras Zootecn. 33, 936-946. 2004.

38. Vega E., Figueredo J. Parámetros hemáticos por sexos de codornices (Coturnix japonica) mantenidas bajo las condiciones reguladas para pruebas ecotoxicológicas. Revista de Salud Animal. 27, (1): 59-61. 2005.

39. Vieites F., Fraga A., Moraes G., Vargas Junior J., Nalon R., Corrêa G., Nunes R. Cálcio, fósforo e proteína total no sangue de frangos de corte em função de níveis de balanço eletrolítico da ração. Arq. Bras. Med. Vet. Zootec. 63, (4): 887-894. 2011.

40. Zakaria H., Tabbaa M., Alshawabkeh K., Altaif K. The effect of dietary sodium bicarbonate on performance and blood parameters of broiler chickens and local Balady breed inoculated with Salmonella gallinarum. Journal of Animal and Feed Sciences. 18, (2): 335-347. 2009. 